\title{
The Spiritual and Cultural Perspective of Xinjiang Nomadic Nationality Traditional Sports
}

\author{
Liqun Peng ${ }^{1}$ \\ Physical Education College \\ Xinjiang Normal University \\ Urumqi, Xinjiang \\ xjplq@163.com \\ Baoqing Wang ${ }^{3}$ \\ Physical Education Department \\ Xinjiang University of Finance and Economics \\ Urumqi, Xinjiang \\ 15899152031@qq.com
}

\author{
Shuai Cheng 2 \\ Physical Education College \\ Xinjiang Normal University \\ Urumqi, Xinjiang \\ 77747800@qq.com
}

\author{
Tao $\mathrm{Liu}^{4}$ \\ Physical Education Department \\ Xinjiang University of Finance and Economics \\ Urumqi, Xinjiang \\ zuqiubaoshi@126.com
}

\begin{abstract}
The methods of literature and fieldwork were used in this paper to research the Spiritual and cultural perspective of Xinjiang nomadic nationality traditional sports. The results showed that displays in. Heroes and performer competitions are admired by people. The sports plain organism's habits melt into express people is delightful, Beg for fine life of good fortune spirit carrier. Both of them are the competition performer and audience; Take sports games and entertainment seriously, look down upon individual material gain and official career; Enjoy grasslands and peculiar mental realm of fields on a hill sports culture. The factor soft and floury affecting the Xinjiang nomadic people tradition sports spirit cultural layer has: Psychological changes of nomadic people is affecting development of traditional sports; Religious belief is blocking nation traditional sports carrying out objectively; Psychology reduction the nomadic people is competed for affects national tradition level of sports rise; Some nomadic people traditional concepts are restricting development of nation traditional sports.
\end{abstract}

Keywords-Xinjiang Nomadic people; Traditional sports; Spiritual culture

\section{INTRODUCTION}

The Xinjiang nomadic people are included Kazakh, Mongolian, the Kirgiz nationality, the Tajik nationality. More than 1,900,000 are common populations. The four national minorities are tradition life-style nations be staying in the world nowadays. One thousand years history evolution and social development, It has been fraught with traditional sports of variety and flourish culture under effect producing life-style and a lot of factors to Xinjiang nomadic nationality .such as grasslands fields on a hill culture, in specific historical conditions, peculiar ecological environment, Whose historical values, social value and cultural value all are to be difficult to estimate. Xinjiang nomadic people traditional sports culture includes material culture, system culture, mental cultural. Spiritual culture has shown aspect such as people's sports values, mental disposition, paths of thinking then. The article is trying to analysis the spiritual culture of Xinjiang nomadic people traditional sports, promoting the sustainable development of Xinjiang national tradition sports culture.

\section{OBJECT OF STUDY AND METHOD}

\section{A. The Objects of Study}

The traditional sports of Kazakh, Kirgiz, Mongolian, Tajik in XinJiang Uighur Autonomous Region as well as culture which derived from them were chosen as the objects of study.

\section{B. The Methods of Study}

Methods of literature and fieldwork were used mainly in this paper.

\section{RESUlTS ANALYSIS}

Xinjiang nomadic people are distributed in north and south of Xinjiang Uighur Autonomous Region, they live in grasslands and fields on a hill rising 1500- 5000 meters high. The population of Kazak is mainly in fields such as $\mathrm{Yi} \mathrm{Li}$ Kazak Autonomous district, Tacheng Prefecture, Altay Prefecture and other regions. The population of Mongolian is mainly in fields such as Profile of Bayinguoleng Mongolian Autonomous prefecture, Bo Er Ta La Mongolian Autonomous Prefecture.The Kirgiz nationality population is distributed in Kizilsu Kirghiz Autonomous Prefecture. Main the Tajik nationality population distribution waits for a field in Ka Shi Territory Ta Shi Ku Er Gan town Tajik nationality autonomous county. The Xinjiang nomadic people chase waterweeds at the all seasons but perch, live law without leaving out the monotonous nomadic life obviously. Xinjiang nomadic people traditional sports come to103 items. Among them, Kazak there is the male and female love play, horse race, Kazakhstan hold sheep, Kuresi in the mouth, the horse throws 42 items such as whip etc. Mongolian has 16 items such as horse race, cover horse, archery, Boke. the Kirgiz nationality has the cover horse, swiftly, the horse picks up a silver dollar, the Kirgiz nationality holds a sheep in the mouth , pursues a girl 138 items 
and so on. The Tajik nationality has eagle 16 such as dance, polo, matching poeephagus grunniens. All these traditional sports have become their entertainment way of living. These traditional sports accumulate a shallow lake being all bearing the weight of culture thick and heavy. Have forged out their distinctive national character, a silent transforming influence of field has formed distinctive mental realm of nomadic people.

\section{A. Hero and the Athletic Contest Performer in War is That People Adore and Respect}

The Xinjiang nomadic people has the national hero adoring and revering in their mind, But hero worship has also become the important pillar structuring national spirit value orientation. Always, the hero steps forward bravely, takes the lead during the period of the outside enemy's invasion, the people suffer humiliation, place life and death in the degree outside, lead the masses and the aggressor to be at bay in a fierce battle. Hero worship is recorded mainly in having on Kazak, Mongolian nationality, the Kirgiz nationality, the Tajik nationality ancestry, slogan and heroic epic. The national hero is the nation backbone. Understanding the nation advocating a hero is really hero's nation. One of the great traditional and value orientation respecting a hero, proposing heroic spirit to Chinese nations. In the peacetime athletic contest, people sometimes mentions hero in beating person and war on the competition obtaining in the same breath. In having fun in fierce vivid competition, being that the nomadic people takes a fancy to more brings about Xinjiang as long as process, being able to happy .Get rid of the result vexation will be best immediately. Weight can explain a problem probably more in participating in this comparatively simple sports cultural spirit. That the Xinjiang nomadic people participates in the people who holds sheep competition in the mouth to special respecting disregarding he is to win is to convey a hero, look upon them as for instance. It makes people who participate in holds a sheep in the mouth but even to those, people looks upon the person as the coward, contempt that can accept people then.

\section{B. The Sports Plain Organism's Habits Melt into Express People is Delightful, Begging for Fine Life of Good Fortune Spirit Carrier}

The Xinjiang nomadic people live in poor natural circumstance. That they constantly strive to become stronger, the indomitable and hard bag combats, has created out splendid sports culture ultimately. Without opitmistic character and the life attitude making progress actively are very difficult to achieve. The Xinjiang nomadic people wear splendid attire, singing and dancing with happiness or hold all kinds of sports activities, horse race, hold a sheep in the mouth, the girl goes after to have become express the spirit carrier delightful, begging for healthy life. Arrange to the attitude is graceful, clothes and ornaments are gorgeous, motion, healthy and strong. Have demonstrated colour and lustre of life for healthy and strength.

\section{Be Good at Writing and Martial Art, the Strength is Elegant}

Always in the past, the Xinjiang nomadic people live in mountains and grasslands, the spirit that such very bad living environment and living conditions have made them to pursue the mental of natural life. However, the insufficiency contacting with the external world has brought about indomitable acting on dogged will and independent family economic units. They have to struggle in training their risky, brave, hiking, progress and so on in order to live in .natural for lasting for survival. Of course in this process, existence endures, compromises, obeys to wait for the inertia spirit element. Natural instincts exactly being that they offer worship as a tribute, run after sudden huge profits because of nation self's individuality element has achieved. It's no hard to understand that a region why slices down the ages in northwest country. War has become a kind of catalysator, promoting their literature, martial art, graceful art using influence hitting the target in Xinjiang nomadic people multiplying for as a kind of spiritual culture element being able to be used especially. For instance: Wrestling in Xinjiang nomadic people traditional sports and immediately, sports item all is brave and powerful, firm display the male sex, the strength is an aspect of expressing passing oneself limb in the process of activity. Characteristics such as soft, quiet, beautiful in these traditional sports culture and Central Plains area traditional sports culture has formed organic complementation, combination extremely large rich our country traditional sports culture resources esteeming force culture and gentle sinister culture, culture has provided more material and space for development to the traditional sports diversifying.

\section{Everyone is the Competition Performer and Audience}

The Xinjiang nomadic people are live in a compact community in our country northwest frontier, which is influenced by foreign culture. As a result, the Xinjiang nomadic people do not have depths of affecting by the Confucian culture. The Confucian culture assumes that the fundamental spirit includes neutralization, the Doctrine of Mean concept. A topic idea is to make us accomplishment conscientiously, supervise, educate, improve and perfect, Confucian learning ought to have the Great Harmony idealism thought with the whole world as one community at the same time emphasizing people in the world, weight says that the light implement, the idea emphasizing civil administration at the expense of national defense are extremely grave. But under this culture atmosphere effect, big multiple that the Central Plains traditional sports culture shows then civilize, say a grade to advocate gentle US, that Xinjiang nomadic people traditional sports culture exercises mainly is not to be dependent on the school education pattern for the basis, propagation, reason why being mostly that aggregation, the gregarious chance carry out knowledge and culture by the fact that the various grand gathering waits for crowd, the city shows whose tradition of this nationality sports activities when the Xinjiang nomadic people. Man is holding grand folk custom festival. Make a general observation of present harbouring the tradition sports item staying in the world as before, such as: Horse race, holds a sheep in the mouth, the girl goes after to wait for a project to be mostly the sports item that two people or many people participates in, and in exercising regulation middle and not having restriction on participator dignity and the request, also only, the unique difference is self attach importance to participator's competitive level, but is not social status. Xinjiang nomadic people traditional sports does not fix like flexible space, equipment and material, that audience and the performer have 
neither had obvious differentiation, one aspect has displayed oneself to others, is to express a fine platform appreciating them at the same time. Project reason why, Xinjiang nomadic people traditional sports are exercised unlike modern competitive sports of west, only when the athlete selected for a sports meet is ready to participate in competition, can devote into come in. This attaches importance to participation, the group feels strong spiritual culture and that the Xinjiang nomadic people exists is to have inevitable connection, the feasible Xinjiang of bad weather condition and environment nomadic people is accustomed in collective school assignment, this collective consciousness brings up the major factor being spiritual culture's turn also right away.

\section{E. Takes Sports Games and Entertainment Seriously, Looks down upon Individual Material Gain and Official Career}

Xinjiang nomadic people traditional culture does not have in the middle if Central Plains culture is general, does not teaches whose "laziness in youth spells regret in old age a common saying since childhood, does not exhorts son or daughter to concentrate on their studies, step into official career in one day, just may be entrenched in a high position and receive privileged treatment. The Xinjiang nomadic people are to run after naive freeness and easiness of one kind of liberty but they do not praise highly "All occupations are base only book-learning is exaled idea. Therefore, they provided the possibility that Xinjiang nomadic people tradition sports activities have come into developing space right away. In ancient times, Central Chinese people get rid of martial art or writing mostly, do not encourage traditional sports to use personal influence, suspicion of thinking that the person has playing through life and having no serious ambition, kind of traditional sports is flexible even if existence is certain, they are also as far as possible with one kind of extremely elegant way coming on the march, sacrifice the component taking exercises. This feasible much tradition sports are fine for dying young within one posterior stage in initial stage development, such as: Piece, supporting play, kicking a ball and so on. Looking back at Xinjiang nomadic people traditional sports culture is extremely close add game possibly in various tradition sports, enriches the entertainment exercising self during the past forms such as poetry song, dance and music. This expressive and unrestrained spiritual culture has brought up sports spiritual culture which is not manufacturing to some extent, one silk has been not heavy, the splendid movement needing but revealing out of responding to the heart completely. Exactly eager about free and easy since the people is hit by liberty to life, feasible traditional sports does not add material gains and the secular component in the activity. It is just because what the so-called the culture not having a quilt if as central plains trend of thought throttles. These lose the activities existing down expressing a way that great majority also are to relaxing, give vent to emotion as people one kind, give first place to these activities wait for the kind lying fallow mainly with game therefore, participate in taking people as the main body, component color exercising self not number skill.

\section{F. Enjoy Grasslands and Peculiar Mental Realm Of fields on a Hill Sports Culture}

Grasslands and fields on a hill sports culture show an atmosphere, and as one kind main Smriti approach, the choice becoming their life-style. Grasslands and fields on a hill sports culture carrier are where person, they go to the culture taken where to arrive at right away. The mentality is therefore likely to the nutriment molding a sum. Enjoyment shows three respects of mental realm: The first: Person and horse union atmosphere are US. That the nomadic people develops gradually living is to take horse as a partner, the horse already has been not one kind of average animal, but one kind of sage thing at herdsman's heart, one kind of inclusion can stimulate life rich content and spirit image. Pass people's domestication and look after and tame, make Ma Ke reach one kind be over all potential. Often may produce one kind of rhythm while the horse runs in disease speed, the messenger people immerses in this rhythm carefree and happy and nature restrains to move middle. Second: Festival convention atmosphere is beautiful. In Xinjiang nomadic people 17 tradition festivals, every festival holds tradition sports activities of colour and variety, understanding for chance, exchanging, interchanging feat's by the fact that the festival party increases people's mutuality. In Xinjiang nomadic people wedding and funeral, totemism, ancestor worship and the ceremony living, sports culture is essential content. Grasslands and fields on a hill nomadic people traditional sports are exercised, Mark of not having the performer and audience, every individual is both actor and audience, both show self and show solicitude for others, it is unlike modern competitive sports. Be one kind of peculiar culture phenomenon. Third: Free psychology atmosphere is beautiful. The Xinjiang nomadic people is not more since the bag is hard, contact with the external world, independent concept having brought up people. They do not have the reason concept clear and definite to liberty, do not are only one kind of hobby, one kind of mental orientation, one kind of mental outlook. Express self thought thereby. [1 ] [1] Xinjiang nomadic people this peculiar grasslands sports culture mental realm has shown the essential strength that the nation works, the survival having satisfied a nation has needed, the mentality having reflected a nation has faced together, have shown the ideal nation value image.

\section{G. Affecting the Factor of Xinjiang Nomadic People Tradition Sports Spirit Cultural Layer Soft and Floury}

1) Psychological changes of nomadic people is affecting development of traditional sports

Because of special geographical environment, the Xinjiang nomadic people ploughs with the agriculture or takes animal husbandry as the basis society, have brought up look down upon engaging in business mental consciousness in whose ethics standard and culture tradition, have formed intense commodity economy consciousness and commerce concept now. Wealth such as cattle sheep, horse and money association consciousness are thereupon especially strong. Develop from natural economy or semi-natural economy to all-round concept of the market. The concept competing for concept, opening concept, safety intensely has also appeared, has consumed concept and has studied concept. That these concept change, causes development of some of Xinjiang nomadic people traditional sports to fail to adapt to the request being modernized, has made whose Smriti accept effect with developing. 
2) Religious belief is blocking development of nation traditional sports objectively

Religion and folk custom are that the human culture long range history accumulates a shallow lake, it takes form and develops to be affecting people's ideology, habits and customs, behavior. Xinjiang is a areas inhabited by the minority nationalities, development of athletics has long been under religion and the folk custom various affects. For instance: The Xinjiang nomadic people is believed in mostly Islam, since whose religion forbids a female to reveal any body's location before male person, but daughter athletes clothing, headgear and footwear has violated Islam religious doctrine, reason why exactly gravely female, south Xinjiang belief Islamic female, pole stop participating in nation traditional sports especially. Besides, Xinjiang still has a few national minority, the person rather utensil national culture characteristic clothes and ornaments, headwear miscellaneous and trivial, being participated in nation traditional sports bringing about an obstacle by people as well as etiquette complicated and overloaded is flexible, play have arrived at blockage nation traditional sports is open-minded role objectively.

3) Psychology reduction the nomadic people is competed for affects national tradition level of sports rise

The concept seal off will lead to the reduction competing for range atrophy and competition directly. Do not come to mention in the big mound. The analysis competing for psychology indicates the national minority leaning on bright going into the society and developing lower Xinjiang of circumstances greatly" in studying: Every Xinjiang nation there is existing certain difference in aspect in the field of national tradition, language and culture, religious belief etc. , is living in narrow and limited and enclosed as well space plus Xinjiang national minority long range, is competing for natural characteristic property, reason why being person nearby, the consciousness they are competed for on one hand is very light, another aspect does not widen because of the field of vision, the range competing is very narrow and limited , the person (or thing) outside their very difficult general this nationality, our region looks upon as self competitor (or range), also be insufficiency the whole world mental consciousness, Very obviously, this is not in harmony with each other with the development idea and trend that the present age national tradition sports moves. The consciousness therefore, competing is light, the reduction competing for psychology will affect national tradition sports activity level rise.

4) Nomadic people's traditional concepts are restricting development of nation traditional sports

But do not hesitate to modernize every Xinjiang national minority in course also all in having advanced scientific and cultural knowledge and advanced office procedure in hand, do not use advanced modern times to arm self come idea , concept, consciousness unceasingly, the national minority traditional concepts still has the comparatively obvious brand left in the heart in people. For instance: "You stepfather already "is be logical and natural , perfectly justified within Xinjiang nomadic people occupation concept, this "combines with patriarchal system but, whose effect it is the enterprising spirit strangling person, to be harmful for person to broaden self's horizon, diversity bringing people's activity and hobbies into play also $\mathrm{Bu} \mathrm{Li} \mathrm{Yu}$, this concept has young successor endowed by nature can not be engaged in national tradition athletic sports, but must get rid of the identical person job inheriting ancestors very much also with regard to feasible national minority middle few. Therefore, be in this Xinjiang areas inhabited by the minority nationalities, some traditional concepts in nomadic people is restricting development of national tradition athletic sports.

\section{REFERENCES}

[1] Li Ping.Grasslands sports culture group atmosphere appreciation of the beauty characteristic [J]. Sports culture leads publication 2005 (12): 49 50

[2] Xinjiang Uighur Autonomous Region nationalities affairs commission. Xinjiang tradition of ethnic minority athletic sports project assembly [M]. Urumqi:Xinjiang people's publishing Press. 2005

[3] $\mathrm{Na}$ are pulled. Society analyses the Xinjiang nomadic people [M]. Beijing: Nation publishing house. 2005

[4] Ling Jing .The athletics characteristic takes that Xinjiang Kazak plays immediately as analytical case immediately with developing a countermeasure- [J].Sports and science. 2007.28 (5): 71 - 73

[5] Abulai are mentioned $\cdot$ Comply with Ming Dynasty. The lower Xinjiang of go into the society and big exploitation circumstances national minority competes for psychology analysis [J].Xinjiang normal school college journal. 2002. (3). 37-41

[6] Zhu Mei Xin, Zhang Xin Hui .Li Jin Guo . Xinjiang nation traditional sports humanity geographical features studies [J]. Xi'an sports institute academic journal. 2009. (1): 49 - 51 